The ope ation which suggested itself was as follows. Under an anæsthetic the bladder was emptied and injected with four ounces of boric lotion; a transverse incision was made across the hypogastrium one inch above the symphysis pubis ; this incision enabled one to get a more extensive view of the bladder. The recti were separated in the middle line and retracted and a good view of the bladder was obtained. The urachus was then sought for, but the left obliterated hypogastric artery came into view as it seemed somewhat anteriorly placed. On prolonging the separation of the recti upwards the peritoneal reflexion was well displayed with the omentum and small intestine below it. By working the finger up between the fascia transversalis and the peritoneum the fibrous structure of the urachus could be felt lying on the lower plane and deep, not just under the abdominal wall as one is apt to imagine. The urachus, which was of the size of a clay-pipe stem, was seized and bared to the extent of one and a half inches. The part quite close to the bladder was clamped, while another clamp was applied one inch higher up. The part between was divided and the two ends were touched with pure carbolic acid and ligatured with catgut. A purse-string suture of celluloid thread was then made round the vesical stump of the urachus, going through the muscular coats of the bladder but avoiding the mucous. The stump of the urachus was now invaginated into the bladder and the purse-string was drawn tight, just as the appendix stump is buried in the cæcum after appendicectomy. The umbilical end of the urachus was brought

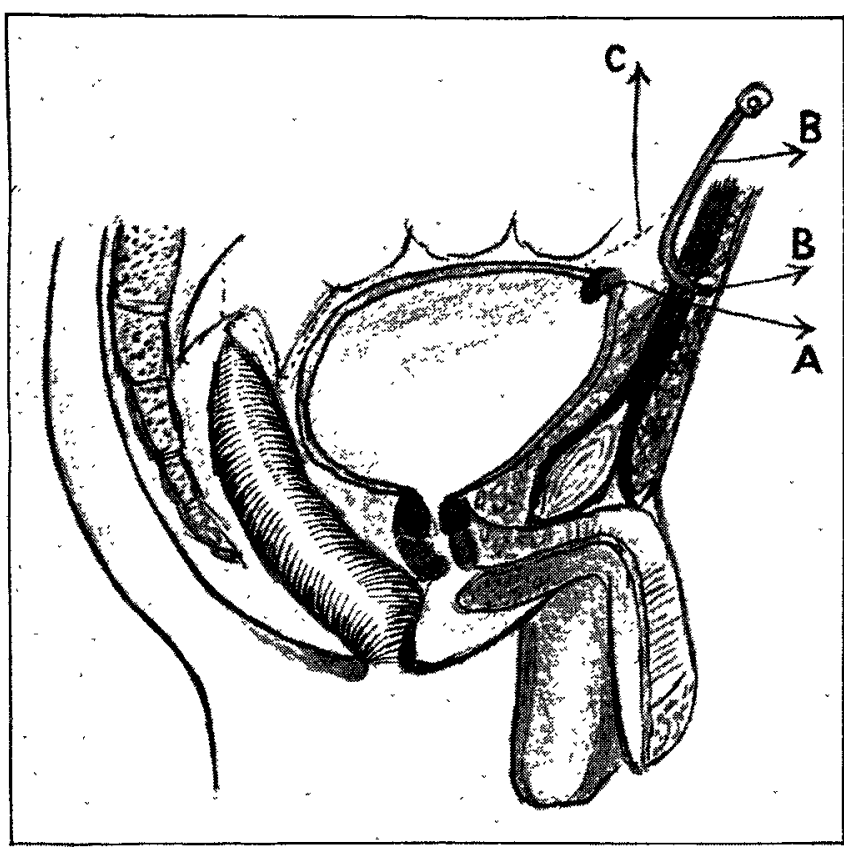

Mesial section showing the appearance of the urachus after the radical operation. The visceral end $(A)$ having been ligatured and cauterised is invaginated through the vesica wall, the wall being closed over the stump by a purse-string suture of celluloid thread. The umbilical end (B), also ligatured and cauterise?, is brought through the recti muscles and fixed under the superficial structures of the abdominal wall. The peritoneum (c) is unopened.

up outside the abdomen and through the split recti and anchored there to the muscle and sheath and left under the skin and fascia only, so that both ends were treated extraperitoneally on account of the eczematous condition at the umbilicus. The wound was then closed in the ordinary way and the patient was put to bed with a catheter passed per urethram. The catheter was removed after 48 hours and the bladder allowed to act spontaneously, which it did painlessly and without leaking. Recovery was uneventful and the patient went home in a fortnight much better. The excoriation about the umbilicus still persisted for several weeks but is now much better (three months after the operation)

This obstinacy is no doubt due to the secretive activity of the squamo-cubical epithelium of the mucous lining of the upper end of the urachus. Should any difficulty remain in this part one should either rescet the remainder of the tube or destroy its lumen with escharotics. The hypertrophy of the urachus from increased work is noteworthy when one compares it with the shred left in a normal person when the allantois hes undergone its normal embryonic changes.

Lancaster.

\section{NOTES ON A SERIES OF OPERATIONS FOR THE ACCIDENTS AND COMPLI- CATIONS OF GASTRIC ULCER.}

By G. REINHARDT ANDERSON, F.R.C.S. ENG., HONORARY MEDICAL CFFICER TO THE SOUTHPORT INFIRMARY.

THE accidents and complications of gastric ulcer prove a fruitful theme in the columns of modern medical literature. Since the time, not so long ago, when the successful treatment of a perforated gastric ulcer (one of the direst accidents that can befall a human being) was heralded as a great surgical triumph, many cases have been recorded. It has become an axiom that the early recognition and prompt treatment of this accident afford a great prospect of success. There is no patient so afflicted but should have a chance given him; no practitioner if placed in circum. stances of extremity but should be capable of giving relief in such an emergency as early as he would were it a case of strangulated hernia. So I am prompted, writing as a general practitioner, to give briefly the results of the cases that I have treated in the past five years. Undoubtedly many cases of sudden severe abdominal pain with concomitant symptoms (involving the rupture of a gastric ulcer) are overlooked and thereby lost because there lies at hand the ready hypodermic syringe, the delusive soothing of morphine with the consequent and often fatal delay-a temptation that readily assails the practitioner, as, indeed, it did with me in my last case where, with few symptoms, a patient reluctant to undergo an operation, and a midnight hour, I was sorely tempted to give morphine a trial and see how things looked in the morning. Fortunately I resisted the temptation with the results to be shown below in the first case recorded. In these cases it is most necessary-if once assured of our diagnosis-to urge immediate operation, for experience again and again proves that our chances of success are immeasurably greater if the operation is undertaken soon after the perforation. It is the early recognition of the severity of the case that I would urge as all-important, for so many cases coming into hospital are moribund or nearly so. These remarks refer especially to the sudden rupture of a gastric ulcer with its inevitably fatal result if unrelieved. In regard to the complications of gastric ulcer the way may be not so clear or so easy. In this class we meet with cases either of intractable dyspepsia or constant emesis or chronic hæmorrhage with many allied conditions the outcome of long existing gastric ulceration. The medical treatment of these cases often proves to be entirely unsatisfactory and we are faced with the difficulty what to do to relieve them. In a large majority a posterior gastro-enterostomy holds out the prospect of renewed health and comfort, and it may be offered to a patient with rapidly diminishing risks. It is no part of my intention to enter into a detailed examination of the conditions in which this operation may be indicated, nor to describe its technique, but in my own experience I have come to recognise six cardinal points as being essential in its performance: (1) the site of junction-namely, the posterior aspect of the stomach as opposed to the anterior whenever possible and in but few cases is it impossible to effect a posterior junction; (2) shortness of the loop of bowel as measured from the duodeno-jejunal angle; (3) the obliquity of the incision into the stomach-namely, from below upwards ; (4) approximation as near as possible to the greater curvature; (5) removal of superfluous gastric and intestinal mucous membrane; and (6) immediate suturing with fine silk by an inner and outer layer together with the use of clamps during the process of suturing. These points, I know, have been urged by others, and my experience convinces me that they are essential.

In my earlier cases regurgitant romiting was not unknown, but since following these points during the past 18 months not one of my patients has had regurgitant vomiting. To me the shortening of the loop seems all-important. In the after-treatment I lay special stress upon the importance of pillowing the patient up in a semi-recumbent position as soon as the anæsthetic sickness has passed off and the wisdom of early judicious feeding. Bearing these points in mind and having regard to a selection of cases, excluding those in whom disease has reduced the bodily powers so much as to 
impair the prospect of union, I believe we may confidently offer to our patients by this operation great relief from their sufferings and a measure of health undreamt of before. I will first turn to the consideration of the cases of perforated gastric ulcer.

CASE 1. Perforated gastrio ulcer, ocourring twice in a year, the second operation aocompanied by gastro-enterostomy.-The patient was a female, aged 22 years. The first perforation occurred on May 17th, 1903. There was a history of gastric pain and vomiting over several years. She had been under my care for the previous 12 months. On the afternoon of May 17th whilst asleep in a chair somebody entered the room hastily and gave her a fright. This was immediately followed by sudden acute pain in the abdomen. She was first seen at 5 P.M. ; the pulse was rapid, the temperature was $100^{\circ} \mathrm{F}$., the expression was anxious, and every movement gave pain. She complained bitterly of pain in the left shoulder tip (a symptom that I have found not uncommon in these cases), the abdomen was distended, and the liver dulness was lost. I diagnosed a perforated gastric ulcer. She was removed to the infirmary and I operated at 8.45 P.M., four and a half hours after the perforation. An ulcer was found on the anterior wall of the stomach. There was little or no extravasation of the stomach contents into the peritoneal cavity. I excised the ulcer and the resulting wound in the stomach was secured by two layers of silk stitches. The peritoneum was freely douched with hot saline solution, and no drain was used. Recovery proved uneventful. She left the infirmary in a month. Progress for six months was satisfactory; she had no pain after eating and remained in the best of health. I saw her again at the beginning of this year, because she was complaining of pain under the tip of the left ninth rib, which she described as of a dragging character. It was not aggravated by food. I suspected an adhesion resulting from the operation and advised rest in bed, great care with diet, and, if no relief resulted, to have the abdomen opened to investigate the cause. The patient was not seen again until May 29th, 1904. She had been off and on well since my last visit in February, sometimes free from pain and at others suffering severely, but it now had relation to food. She stayed in bed on May 25th and 26th for this same pain, but on the 27th and 28th she had been better and freer from pain than at any time since the operation. During the afternoon of the 29th she played croquet and afterwards ate a full tea of ham and eggs, and subsequently went for a walk. At 9.15 P.M. or thereabouts she had a drink of milk and soon after complained of severe abdominal pain whilst walking in the street. This was so bad that she had to get a cab to take her home. I first saw her at 11 P.M. and found the abdomen not very distended, but acutely tender to palpation, more especially over the left hypogastric region and in the epigastrium. The liver dulness was slightly diminished, and there was much rigidity of the abdominal muscles. She had vomited and was constantly making slight attempts at regurgitation which brought on severe pain. She could not micturate although there was a constant desire so to do. The pulse was 132 , respiration was almost entirely thoracic, the tongue was furred, the breath was offensive, and the temperature was $100 \cdot 4^{\circ}$. I suspected perforation, although the symptoms were so vague, and strongly urged an exploratory operation. It was now that she begged for morphine and wished me to leave her till the morning, but I absolutely declined. Hence some delay took place and it was not until $1.45 \mathrm{~A} . \mathrm{M}$. on the 30th that I was able to operate-four hours after the perforation.

On opening the abdominal cavity many firm adhesions were encountered binding the stomach to the abdominal walls and to the liver; great difficulty was experienced in separating the stomach and when this was done the position of the old ulcer was easily made out, quite obliterated, but in the stomach wall in this position I could feel the silk that had been used in the previous operation. The stomach itself was very much congested. No free gas escaped from the abdominal cavity and there was not much evidence of soiling beyond stray flakes of lymph, so that I doubted at first whether a perforation had occurred, but on gently drawing the stomach into the wound a fresh ulcer fully four and a half inches from the site of the previous perforation came into view with a minute perforation in its centre. The ulcer was close to the lesser curvature and from its proximity to the cesophagus difficult of access. It was of about the size of half a crown, very cartilaginous, and the margins of the perforation were hæmorrhagic in appearance. I found it quite impossible to excise, so closure was effected after some difficulty by two layers of fine silk sutures and a piece of omentum wap anchored over the site to give additional security. I determined, in view of her good condition at this stage of the operation, the absence of any severe peritonitis, and to prevent the possibility of recurrence, to perform an immediate posterior gastro-enterostomy. This I did as quickly as possible. Subsequently I douched out the peritoneal cavity with large quantities of hot saline solution, a great deal of which being left in, the abdomen was closed in the usual way. No drain was used. She stood the operation very well and, her subsequent progress proved uneventful. There was no regurgitant vomiting; in fact, she has never vomited since the operation. She left the hospital in a month. Her present condition is one of gradually improving health.

CASE 2.-The patient was a female, aged 21 years, having a previous history of gastric trouble. Perforation occurred three hours after a hearty meal. The operation was performed two and three-quarter hours afterwards. I discovered a small perforation on the anterior surface which was easily sutured. Lavage was used but no drain. She made an uninterrupted recovery except for some effusion into the left pleura which subsided without tapping.

CASE 3.- The patient was a female, aged 24 years. There was a vague history of previous gastric disorders. The symptoms commenced three days before she came under my care. She had had violent abdominal pains and vomiting, but as she continued to eat heartily till within 24 hours of admission this was hardly to be wondered at. When I saw her the temperature was $101.2^{\circ} \mathrm{F}$, the pulse was 140 , and she presented all the signs of acute appendicitis. A large incision was made over the cæcum but I soon saw that I had to deal with a subacute perforation of the stomach. A further incision was made over the epigastrium and my examining finger entered an irregular cavity which was bounded below by the pylorus, externally and above by the lesser lobe of the liver. From this stomach contents were escaping. No attempt at closure was made or was possible. Gauze was packed into the cavity and a big drain was put in the lower opening. Strange to say, except that it was prolonged her recovery was uninterrupted. On the fourth day I extracted a piece of bacon from the upper wound, proving at once the correctness of my diagnosis and the tolerance of the much. abused peritoneum.

CASE 4.- The patient was a female, aged 17 years. There was a long previous history of stomach pain, \&c. The first symptoms of pain occurred two days before acute illness. Operation was performed approximately 14 hours after perforation. A perforation on the anterior wall of the stomach was easily found and sutured. There was no lavage, only systematic mopping. A small gauze drain was inserted. Recovery ensued without a bad symptom. Her temperature was $101 \cdot 2^{\circ} \mathrm{F}$. before the operation and the pulse was 122 . In three days the temperature was normal and the pulse was 88.

CASE 5.- The patient was a female, aged 23 years. We have very little history of this case. She was admitted to the infirmary 20 hours after perforation in a moribund condition. Operation was performed 23 hours after perforation. On opening the abdomen the peritoneal cavity was literally awash with dark brown fluid. The perforation was close to the pylorus and very difficult to suture. Every attempt was made to cleanse the peritoneum by lavage and a suprapubic drain was used. She died seven hours after the operation.

CASE 6.-The patient was a woman, aged 38 years. This is one of the most interesting and instructive cases that 1 have seen and is the record of a success and a failure. She was a weakly woman, the mother of ten children, and with a history of gastric ulceration extending over many years. On the morning of Dec. 14th, 1902, in the act of micturition she was suddenly seized with acute pain in the left oroin and over the bladder, so severe that she nearly fainted and had to have brandy. I saw her at 3 P.M.; she then presented the following curious train of symptoms. There was a left femoral hernia which was quite recent bat which I was able to reduce without difficulty. The abdomen was not distended nor hard; it was exquisitely tender over the epigastric region but she persisted that the chief seat of her trouble was in the bladder. The liver dulness was unaltered and there was no free fluid in the flanks. Her 
tongue was only moderately furred, there was no vomiting, and the temperature was $100 \cdot 4^{\circ} \mathrm{F}$, but her pulse was thin and rapid at 128 . In spite of these vague symptoms I decided to operate and did so eight hours after perforation. On opening the abdomen I found on the anterior surface in the outer third a large indurated gastric ulcer of about the size of a five-shilling piece with a tiny perforation right in the centre of it. I had to excise the ulcer and then brought the big gaping wound together in the usual way, the final fold in the vertical axis being quite four inches long. Lavage was used and a suprapubic drain. All went well for five days when she began to get true regurgitant vomiting. We tried all possible means to stop it by syphonage, \&c., but ineffectually. So on the evening of the seventh day, recognising that she must have pyloric obstruction, I reopened the abdomen to find that the site of my previous operation was almost obliterated, so complete was the healing. But what I did find was a very marked hour-glass state of the stomach. The communication between the two compartments only admitted my little finger. This contraction was evidently due to very long-standing ulceration. therefore rapidly performed a posterior gastro-enterostomy. Unfortunately she died from shock in eight hours. My great regret is that I did not discover the whole extent of the stomach mischief at the first operation when, if $I$ had done the two things at the same time, I believe she might have had a better chance.

CASE 7.-The patient was a female, aged 24 years. With regard to her previous history, for some months she had suffered from pain after food and vomiting and her general health had been suffering. She had partaken of a hearty dinner on May 29th, 1903, and during the afternoon had walked a distance of some three miles, when she was suddenly seized with abdominal pain. In spite of its severity she managed to walk home and I was not summoned to see her until 8.15 P.M. On my arrival $I$ found her in intense agony with distended abdomen, constant vomiting, rapid pulse, and slightly elevated temperature. I had no difficulty in arriving at the conclusion that she was suffering from perforated gastric ulcer and advised her removal to the Infirmary. The operation took place at 10.15 P.M. - about six and a quarter hours after the perforation. On opening the abdomen there was a free escape of gas; there was intense peritonitis due to the escape of gastric contents from a large perforation on the anterior wall of the stomach. The ulcer was excised and the stomach sutured with two layers of silk and over the seat of the wound a portion of omentum was anchored. Very careful and systematic douching of the peritoneal cavity was used, followed by mopping in all available pouches. From the extensive soiling of the peritoneum that had occurred I deemed it wise to employ a suprapubic drain and $I$ also passed a large gauze drain down to the site of the wound in the stomach. For 14 days her progress was uneventful. There was considerable oozing from the pubic drain and also along the track formed by the gauze in the upper abdominal wound, but this gradually ceased and by June 12 th both abdominal wounds were soundly healed. On the morning of the 12th she complained of not feeling so well, with a pain in the left axillary region. Examination revealed friction and some dulness over the left base posteriorly. Early in the morning of the next day she had a rigor and the temperature rose to $103.4^{\circ} \mathrm{F}$. Aspiration of the pleura revealed nothing although I quite believed an empyema was forming. The rigors were repeated on several days and the temperature remained very irregular but the pulse was not markedly accelerated nor were her constitutional symptoms bad. Events progressed much in the same condition until the 30 th when she had another slight rigor and again the aspirator was used, and by plunging the needle deeply in between the ninth and tenth ribs $\mathrm{I}$ came upon pus. That afternoon $I$ resected a portion of the ninth rib and on opening the pleura I was disappointed not to find pus. It seemed I had to deal with a subphrenic abscess, so I merely contented myself at this time with stitching the pleura together with a view to opening the deep-seated abscess on a subsequent day. On July 3rd I attempted to find the pus by incising the diaphragm but again my search was fruitless. Therefore I proceeded to make a long curvilinear incision below the ribs and fully exposed the posterior surface of the spleen. This was firmly adherent in all directions and I presume the friction heard was caused by peritonitis localised in this position. With my finger I separated the spleen as far as possible but came upon no abscess. Despairing of finding the abscess by these double posterior incisions I reopened the abclominal wound in the middle line. Apparently everything was perfectly normal; the stomach was quite healed; there was no general peritonitis and I am sorry to say I could in no wise localise the small abscess wherever it was. From this time forward she steadily went downhill. She was seen by Dr. G. Newton Pitt and by Dr. Julius Dreschfeld on more than one occasion. Many attempts were made with aspirating needles to find the pus but all without avail. The physical signs over the base of the left lung were most deceptive. Consolidation with increased voice sounds and amphoric breathing led one to think that a pulmonary abscess was in process of formation, but no evidence of this could possibly be found, the general opinion being that an abscess had formed in the lesser sac but was impossible of access. Palpation of the abdomen gave no pain and it was free from any dull area. From the beginning of August, however, her general symptoms seemed to improve and the temperature began to fall, so that from the 9 th to the 12 th it was rarely above $100^{\circ}$, but on the 13 th it went up to $105^{\circ}$. Her condition became most alarming. Feeling matters were in a desperate state I once again used the aspirating needle, pushing it deeply in between the ninth and tenth ribs. At last I came upon the pus which $I$ had so often sought for ineffectually. Leaving the needle in as a guide I reopened the old wound in the pleura and, following the needle, I came upon a ragged opening in the diaphragm through which offensive pus was escaping. I put in a big tube. Unfortunately the patient died 24 hours after the operation, two and a half months after the original perforation of her stomach.

No post-mortem examination was allowed but the final operation revealed sufficiently the regrettable conditions which led to her death-namely, the slow formation of subphrenic abscess. Possibly the pus which I drew off at the first aspiration emptied the small loculus, so that it became increasingly difficult-nay, impossible-to find it again, as witnessed by the many unsuccessful attempts which were made to reach it both by the aspirating needle and digital exploration. I have no doubt that the fatal catastrophe was brought about by the subphrenic abscess bursting into the pleura and causing a rapid septic invasion.

The consideration of this case opens up that debateable question in treatment--whether douching or simple mopping is the better method of cleansing the peritoneum. For myself, I think that every case needs to be treated on its own merits. Where there has been, as in the above case, copious exit of stomach contents aggravated by walking fully three miles it seems to me that nothing short of lavage followed by mopping would do good. But there is no doubt that free drainage is all-essential and if a drain in the left lumbar region had been used as well as one over the pubes the result might have been different.

The following is an abstract of the cases that I have operated upon for some of the complications of chronic gastric ulcer.

CASE 1.-A married woman, aged 54 years, was admitted under my care to the Southport Infirmary on Oct. 26th, 1901. There was a history of chronic gastric troubles extending: from Christmas, 1897, to the present time. She suffered from severe pain after food with constant vomiting, which at times was of a coffee-brown colour and then very copious. She had been treated in several institutions for the same complaint and whilst she improved under treatment, with the resumption of her work her symptoms rapidly recurred. She had been under my care during 1900, but had now completely relapsed. After two months' stay in the infirmary she consented to operation and accordingly on Dec. 11th, 1901, a posterior gastroenterostomy was performed. A bone bobbin was used. The stomach presented all the appearance due to chronic ulcera. tion. The anterior wall was much thickened near the pylorus, the veins were enormously distended, and there were several enlarged but discrete glands along the lesser curvature. All went well for 11 days when she had a most severe attack of regurgitant romiting. Her condition suddenly became most alarming. She vomited six quarts of bilious fluid in 12 hours. All feeding by the stomach was stopped and it was washed out every three or four hours. By these measures the difficulty was overcome and on Dec. 29th stomach feeding was resumed. Her further progress was uneventful and she left the infirmary on Jan. 14th, 1902, better than she had been for years. I have 
recently heard from her. She is in good health, is able to do her work, is free from pain, and has gained flesh.

CASE 2. -The patient was a man, aged 67 years, who was admitted on August 6th, 1902. His complaint was of constant gastric pain, incessant vomiting, and loss of flesh. Examination revealed a painful area over the pyloric region but no lump could be felt. There was much dilatation of the stomach with subacidity. His urine was free from albumin and sugar but of low specific gravity. His sufferings were so acute that he readily consented to an exploratory laparotomy with a view of performing gastro-enterostomy or otherwise as circumstances might direct. At the operation the pylorus was found to be stenosed considerably and the stomach was very much dilated. A posterior gastroenterostomy was performed and a bone bobbin was used. As far as the immediate operation was concerned he did very well. Within a fortnight he was eating semi-solid food heartily and without pain. He also began to put on tlesh. On the twenty-fourth day after the operation regurgitant vomiting commenced and in spite of all measures adopted this persisted until his death which took place about five weeks after the operation. At the post-mortem examination the kidneys were found to be contracted and granular and I inclined to the view that this condition determined the fatal issue, but at the same time this is open to discussion. The probable explanation from examination of the stomach and bowel is that the loop from the duodeno-jejunal angle was too long. It was the failure in this case that directed my attention so strongly to the importance of making a short loop. At the same time I believe fatal regurgitant vomiting commences much earlier than was the case in this patient. He refused any further operation, otherwise I intended to reopen the abdomen to perform a lateral anastomosis between the two limbs of the loop.

Case 3.-This case I have referred to above (Case 6). It was a complementary operation to the accident of perforation and the patient died within eight hours of performing the same.

CASE 4.-A woman, aged 28 years, was admitted under my care on Dec. 29th, 1902, and gave a very long history of gastric trouble. She had been in St. Thomas's Hospital under the care of Dr. W. M. Ord so far back as 1891. During the early part of 1901 she was admitted to the Southport Infirmary for hæmatemesis and was discharged relieved after a stay of 15 weeks. Hæmatemesis recurred on Dec. 25th, 1902, and for this she again sought admission. From the constant pain and romiting she was so reduced that deemed it best to keep her under observation for six weeks, and under treatment she slowly improved. Operation was performed on Feb. 11th, 1903 . There were well-marked hourglass condition of the stomach and also some stenosis of the pylorus. Posterior gastro-enterostomy was performed with simple suturing and no bone bobbin was used. She made a speedy and good recovery with subsequent absence of pain after eating and a great improvement in general health.

CASE 5. - A man, aged 57 years, was admitted under my care on Oct. 24th, 1903. For 12 years he had been suffering from pain after food. Nine years previously he had severe hæmatemesis. For the past seven years he had made it a practice to wash out his stomach almost every day. A diagnosis of pyloric obstruction was made. On Nov. 7th I operated and found the pylorus so contracted that it would not even admit a small probe. A posterior gastro-enterostomy was performed. There was no regurgitant vomiting and his recovery was uneventful except for the fact that he suffered from troublesome diarrhœea. 'This I think was to be attributed to the fact that the intestines were unprepared for the sudden demands made upon them when he commenced to take ordinary food with freedom and comfort. $\mathrm{He}$ has gained nearly a stone in weight since the operation.

CASE 6.-The patient was a female, aged 28 years. There was a very long history of stomach trouble, vomiting, and hrematemesis. She had been treated in several infirmaries without more than temporary relief. Operation was performed on Jan. 20th. Numerous adhesions were found binding down the pylorus. There was a large ulcer in volving the anterior wall of the stomach. This was adhering to the anterior abdominal walls, leading one to believe that on some previous occasion a perforation had taken place. A posterior gastro-enterostomy was performed and her recovery was rapid. There was no regurgitant vomiting. Before the operation she weighed under six stones and by April 16th, 1904, her weight had risen to 7 stones 6 pounds.

CASE 7.-A woman, aged 42 years, was admitted under my care on Feb. 25th, 1904. She was a fragile little woman suffering from rheumatoid arthritis. She had suffered also from considerable gastric pain and vomiting for many months and in spite of treatment obtained no relief. 'The operation was performed on March 16th. There was a wellmarked hour-glass contraction of the stomach with a large chronic ulcer on the anterior wall and numerous adhesions to the liver and abdominal walls. A posterior gastro-enterostomy was performed and her recovery was uneventful. Her general health improved considerably and she left the infirmary on May 14 th for a convalescent home.

CASE 8.-A woman, aged 49 years, was admitted under my care on April 4th, 1904. Her history of pain, vomiting, and hæmatemesis extended over a period of 20 years. With regard to her present condition, she was a pallid woman emaciated to a degree, complaining of great abdominal pain which was aggravated after taking food. There was marked rigidity of the abdominal walls and a sense of fulness and resistance was felt over the epigastrium. Operation was performed on May 5th. I found a large cartilaginous ulcer involving almost the whole of the anterior wall of the stomach. Its diameter was fully five inches and on invaginating the stomach wall the finger came upon a depression in the ulcer which seemed fully three-quarters of an inch deep. There were so many adhesions that the performance of a posterior gastroenterostomy was exceedingly difficult, but union was successfully effected and her 'recovery was uneventful. There was no regurgitant vomiting. The patient left the infirmary on June 2nd for a convalescent home. I saw her again on June 20th. Her weight, which before the operation was 6 stones $4 \frac{1}{2}$ pounds, was now 6 stones 9 pounds. She was taking her food freely and without pain and the marked pallor of her face was greatly improved.

CASE 9.-The patient was a woman, aged 47 vears. She had suffered from dyspepsia and gastric trouble since 14 years of age. From the Christmas of 1903 she had been considerably worse ; the pain was not only in the epigastrium but also in the left hypochondrium. This was so severe that it had to be relieved by morphine but food often gave temporary relief. Tomiting was not a marked symptom. Dr. Dreschfeld saw her with me and confirmed the diagnosis of chronic gastric ulcer and strongly urged operation which took place on March 17th, 1904. There was well-marked hour-glass stomach which had dense adhesions to the neighbouring organs, particularly one which went downwards and forwards to be attached to the gastro-colio omentum, probably causing the dragging pain she so frequently complained of in that region. Posterior gastroenterostomy was effected with some difficulty as there were so many adhesions. Her subsequent progress was uneventful. There was no regurgitant vomiting. She has gained over a stone in weight since April 20th.

CASE 10.-The last occasion on which I had the opportunity of performing a gastro-enterostomy is the one noted above (Case 1) who had suffered from double perforation.

I am well aware that a series of ten cases is too limited to draw any final conclusions from but they are a small contribution to the mass of evidence that is accumulating as to the benefits to be derived from the performance of a posterior gastro-enterostomy in judiciously selected cases.

Southport.

\section{A CASE OF ACUTE DIABETES INSIPIDUS WITH FATAL COMA.}

By ALFRED H. CAR'TER, M.D. LOND., F.R.C.P. LOND.,

SENIOR PHYSICIAN TO QUEEN'S HOSPITAL, BIRMINGHAM; PROFESSOR OF MEDICINE, UNIVERSITY OF BIRMINGHAM.

THE following case is worthy of being put upon record owing to its rarity. The notes are unavoidably brief as I only saw the case once in consultation and no post-mortem examination was obtainable.

On July 11th last I was called to see a little girl, aged eight years, with Mr. A. E. Hancock of Saltley. The child was reported as being of a nervous and excitable temperament, but, apart from the presence of threadworms in the stools (to which the mother attached no importance and adopted no treatment), she was considered to be in good 